\title{
A EDUCAÇÃO NA PANDEMIA: SOBREVIVEREMOS?
}

\section{EDUCATION DURING THE PANDEMIC: WILL WE SURVIVE?}

\author{
Lilian Cardoso de Mendonça ${ }^{1}$ \\ Rosiane Cristina dos Santos Silva ${ }^{2}$ \\ Sabrina Spagnollo Rossetti ${ }^{3}$ \\ Ana Archangelo ${ }^{4}$
}

\begin{abstract}
Resumo: O presente artigo traz as narrativas de três professoras da rede pública de três cidades, a respeito de suas experiências, angústias e questionamentos em tempos de pandemia devida ao vírus COVID-19. O trabalho foi organizado seguindo uma ordem crescente de acordo com a atuação de cada uma: a primeira, uma professora do Ensino Fundamental I; a segunda, do Ensino Fundamental II; e a terceira, do Ensino Médio. As três narrativas, embora compostas separadamente, encontram-se nas similaridades dos desafios vividos e na procura por uma ressignificação da função docente e permitem concluir que é necessário e urgente pensar a escola como um ambiente de acolhimento ao aluno.
\end{abstract}

Palavras-chave: Pandemia; trabalho remoto; acolhimento escolar.

\begin{abstract}
This article presents the narratives of three public school teachers from three different cities, regarding their experiences, anxieties and questions in times of pandemic due to the COVID-19 virus. The organization of the work follows an increasing order according to the grades each one acts in: the first, a teacher from Elementary School I; the second, from Elementary School II; and the third, from high school. The three narratives, although composed separately, find each other in the similarities of the challenges experienced, and in the search for a redefinition of the teaching role, they also allow us to conclude that it is necessary and urgent to think of the school as a welcoming environment for the student.
\end{abstract}

Keywords: Pandemic; remote work; welcoming school.

\section{Introdução}

A pandemia devida ao vírus COVID-19 trouxe ao ambiente escolar desafios a gestores, professores e alunos, e exigiu, de todos, mudanças significativas, de forma a permitir que os danos ao trabalho letivo fossem os menores possíveis. As experiências vividas nesse cenário e narradas a seguir por professoras da rede pública vêm trazer reflexões importantes sobre essa transição inesperada do presencial "chão da escola" para a atividade remota das plataformas virtuais. Essas evidenciam problemas já existentes que se agudizaram, como a burocracia do sistema educativo, que frequentemente se sobrepõe aos princípios pedagógicos, desgastando mais e mais os profissionais da Educação; a desigualdade na oferta dos serviços aos alunos em situação de vulnerabilidade; e a visão reducionista que ainda vigora a respeito do espaço escolar como transmissor de conteúdos.

\footnotetext{
${ }^{1}$ Universidade Estadual de Campinas, Campinas, São Paulo, Brasil.

${ }^{2}$ Universidade Estadual de Campinas, Campinas, São Paulo, Brasil.

${ }^{3}$ Rede Municipal de Campinas, Campinas, São Paulo, Brasil.

${ }^{4}$ Universidade Estadual de Campinas, Campinas, São Paulo, Brasil.
} 


\section{A pandemia do COVID 19, uma ruptura nos caminhos pedagógicos}

Acho importante começar este texto contando a minha trajetória deste ano, até agora... O ano começou e com ele a euforia de uma nova turma, essa em especial, pois seria de alunos no primeiro ano do ensino fundamental. Amo trabalhar com crianças menores, que normalmente são inquietas, criativas, cheias de vida, ainda estão livres das amarras que a escola, com o tempo, vai lhes impondo. As crianças chegam à escola, e o ano letivo começa.

Fevereiro foi um mês de adaptação dos alunos ao ambiente novo, à dinâmica da escola fundamental, aos espaços, aos colegas, à professora e aos demais funcionários. Em meio a tantas novidades, eu tateava para conhecer meus alunos, entender o que pensam, do que gostam e o que lhes interessa. Enfim, foi um mês de aproximações e muitas relações interpessoais. Março chegou e ainda nos ajustávamos à nova realidade, agora mais tranquilos e próximos. Nossa sala se modificava conforme as necessidades surgiam: cantinho para leitura com prateleiras, tapetes e almofadas, cada ateliê com seu material e organizado para que se aproveitassem das atividades com interesse e alegria. Estávamos nos apropriando desses espaços, dessas dinâmicas e de nossa vida escolar. O ano prometia muito!!

Quando fomos surpreendidos pela notícia da pandemia, inicialmente, parecia tão longe de nós que não nos atacaria. Mas a doença se expandiu pelo mundo e por aqui. Aulas suspensas, uma ruptura sem muitas explicações nem previsões. E agora? A pandemia só piora, e a quarentena é a solução para nos mantermos vivos e com saúde. Uma angústia enorme se abate sobre nós: o que faremos? Afinal, voltar para escola, neste momento, está fora das possibilidades. São muitas questões e incertezas sobre como continuar o ano letivo e nosso trabalho com os alunos.

A Secretaria Municipal de Educação, então, divulga a adoção de uma plataforma digital para as aulas e a aquisição de tablets para os alunos. Vivo a euforia de poder estar conectada de alguma forma com as crianças e a angústia de ter que aprender a dominar um ambiente virtual, com o qual sempre tive muita dificuldade. Adaptações diversas se impõem e descobertas e sensações múltiplas despontam.

Por mais estranho que pareça, a pandemia nos afastou dos alunos, mas nos aproximou dos colegas. Teve início um processo de sucessivas reuniões, pesquisa de atividades interessantes e acessíveis aos alunos. A preocupação comum era possibilitar a integração e a vivência de aprendizagens. Um trabalho coletivo e participativo se estabeleceu entre as colegas. Talvez esse tenha sido o maior ganho desse caos em que repentinamente nos encontramos.

Quando já estava convencida de que poderia ser proveitosa uma vivência virtual, surgiu uma grande pedra em nossos caminhos: os tablets, que supostamente seriam distribuídos aos alunos, não foram adquiridos. Naquele momento, um misto de sentimentos me acometeu: desespero, frustração, raiva e falta de rumo. De que valeria a utilização da plataforma, se nossos alunos não tivessem condições de acessá-la? A pergunta que nos orientou sobre os passos que seguiríamos foi: Como garantir o acesso de todos nossos alunos?

Então, por iniciativa da equipe diretiva da escola, foram adquiridos chips, que davam aos professores acesso a um aplicativo de WhatsApp Business, o que nos permitiu ter uma conta específica da escola em nossos celulares particulares, para viabilizar e agilizar o contato com as famílias. No início do mês de maio começamos a entrar em contato com elas. Nosso primeiro objetivo era reconectar as famílias e os alunos com a escola e os professores, e, sobretudo, saber como estavam vivendo suas vidas. Confesso que falar com as famílias me trouxe uma alegria indescritível, principalmente ao saber que todos estavam bem de saúde. Contudo, ao mesmo tempo, vivia uma sensação de impotência e inércia, logo acompanhada de constatações que acabaram por minimizar tais reações. 
Com a pandemia, as diferenças sociais e econômicas do nosso país estão tendo maior visibilidade. Na educação, isso tem se apresentado, principalmente, pelo acesso às mídias virtuais, tão importantes neste momento para a continuação das atividades escolares. $\mathrm{O}$ direito à educação está garantido pelo artigo 205 da Constituição Federal de 1988. Em 13 de julho de 1990, foi assinada a lei 8.069/90, que dispõe sobre a proteção integral para crianças e adolescentes, conhecida como ECA (Estatuto da Criança e do Adolescente), que, em seu artigo 4, fala sobre a educação e, no inciso I, traz a seguinte redação: "Igualdade de condições para o acesso e permanência na escola". Movidos não apenas pela necessidade de obediência às leis já estabelecidas, mas, sobretudo, pela convicção de que elas são importantes para a construção de uma sociedade mais humana e igualitária, pusemo-nos a organizar nossa jornada nessas novas condições.

Em equipe, decidimos que partiríamos para o planejamento de atividades que pudessem ser impressas e entregues aos alunos, mesmo sabendo que isso exigiria a presença de alguém na escola. Mas nós, professores, julgamos que essa seria uma ação mais abrangente, visto que a escola já se mantinha aberta para a distribuição de cestas básicas e de hortifruti para algumas famílias.

Então, com supervisão de nossa orientadora pedagógica, decidimos produzir algo autoral. Partindo de textos de fábulas, fizemos uma reescrita com ilustrações produzidas pela professora de arte-educação. Pensamos em elaborar atividades que pudessem ser realizadas pelos alunos com autonomia e estímulo. Montamos livrinhos num molde de almanaque infantil, cada atividade criada e elaborada por nós conjuntamente, preservando o princípio dos direitos autorais.

Nosso cuidado com a elaboração das atividades, além da questão legal, está também na certeza de que, como docentes, não cumprimos um papel de meras reprodutoras do conhecimento, mas de produtoras e mediadoras dele. E, atentas ao fato de que, ao mesmo tempo que as mídias virtuais nos possibilitam uma aproximação com as famílias neste momento, elas também trazem o perigo da massificação da educação e um possível empobrecimento da prática docente, valemo-nos da importância atribuída por Selma Pimenta et al. (2005, p. 23), à relação entre professor e aluno na prática pedagógica:

A educação escolar, por sua vez, está assentada fundamentalmente no trabalho dos professores e dos alunos, cuja finalidade é contribuir com o processo de humanização de ambos pelo trabalho coletivo e interdisciplinar destes com o conhecimento, numa perspectiva de inserção social crítica e transformadora.

Infelizmente, neste momento, devido à suspensão das atividades presenciais, não podemos fazer a mediação direta entre o aluno e o conhecimento, porém tivemos o cuidado de montar materiais desafiadores, mas acessíveis, para que outros adultos ou irmãos pudessem auxiliar nossos alunos em casa. Ademais, buscamos, como escola, alcançar todos os alunos. Para tanto, estamo-nos propondo a desenvolver atividades não só na plataforma, mas também impressas, para os alunos que não consigam acessá-las remotamente.

Acredito que estamos vivendo um momento singular e nunca imaginado, que, não obstante, tem me permitido pôr em prática aquilo em que acredito: a docência para mim sempre foi um espaço de reflexão e reinvenção sobre o trabalho. Muito difícil saber se estamos indo pelo melhor caminho, mas o que me tranquiliza e viabiliza meu trabalho é a crença nos princípios que estão nos movendo. Compartilhar experiências e vivências nesse momento nos fortifica e solidifica nossa profissão. 


\section{Vivência e sobrevivência educacional em tempos de pandemia}

Se ser professora na rede pública do Brasil já é, por si, um grande desafio, sê-la, então, no Brasil, em 2020, é uma tarefa maior ainda. Por vezes, em sala de aula, descobrimos que muitos alunos têm nela o melhor momento de sua dura realidade. Ou que ali se faz possível encontrar novas referências para as suas vidas e novos lugares para as suas inquietudes. $\mathrm{O}$ que estamos aprendendo agora, com a pandemia e com a transferência das nossas classes presenciais, com seus gizes em pó e carteiras rabiscadas, para uma sala de aula virtual, é que nós, professores, também encontramos um sopro de sobrevivência naquele ambiente - uma sensação psíquica de proteção que aquele espaço proporciona para os nossos alunos e para nós.

Em meados de março, saímos de nossas escolas sem saber quando retornaríamos e o que seria dali para a frente: a sensação era de abandono, como se estivéssemos descuidando daquele espaço e daquelas crianças; como nos diz Winnicott (1983), éramos mães não suficientemente boas. Mas também saíamos com o sentimento de que, afastando-nos, estaríamos protegendo os alunos. E com o tempo nossas preocupações, inicialmente envoltas em um emaranhado, passaram a visualizar a linha tênue entre a vida e a morte; nossos dias foram guiados pela incerteza humana de estar vivo no dia seguinte e ter vivos os seus.

Santo Agostinho (Sec. IV) ${ }^{5}$ diz, em uma de suas orações, intitulada " A morte não é nada", que "A vida significa tudo/ o que ela sempre significou,/ o fio não foi cortado./ Por que eu estaria fora de seus pensamentos, agora que estou apenas fora de suas vistas?". O autor diz da morte como um processo real, e trago o trecho de sua oração com os dois sentidos, do real e do simbólico, para nós, docentes: nossos alunos sobreviverão? Eles sobreviverão no sentido concreto de continuar a viver? Sobreviverão como alunos, posto o afastamento da escola presencial? Sobreviverão para o professor, que poderá esquecê-los?

Algum tempo após a suspensão das atividades presenciais, o contato foi retomado com alguns deles virtualmente. A primeira sensação psíquica foi a de ter conseguido ofertar o mesmo para todos em uma sala de aula. Porém, essa expectativa seria uma incoerência com os fatos, pois sabemos que, mesmo presencialmente, nem sempre temos êxito em proporcionar um ensino que leve em conta o processo singular de cada aluno. Agora, não sabemos o que estamos conseguindo, pois, embora estejamos enviando mensagens, atividades que elaboramos, e os vídeos que fizemos, não sabemos a quem exatamente elas chegam.

Encontramo-nos em uma terra devastada pelas mortes que presenciamos todos os dias e pelo afastamento de nossos alunos dos nossos olhos. Eles estão fora de nossas vistas, mas estão bem? Estão se alimentando? Estão tendo amparo emocional para vivenciar tudo isso? Como estão nossos alunos?

Além de termos que lidar com tantos questionamentos e incertezas, também somos abatidos por um desamparo de instâncias maiores que não apreenderam o momento e suas necessidades da maneira como deveriam; ou então fizeram o que conseguiram. E precisamos aceitar o que temos; ficar com aquilo que podemos. Foi assim que a mensagem de um aluno, entre 30 alunos, fez-se como um sopro de sobrevivência para a professora amedrontada; já que a comunicação com os alunos estava difícil de ocorrer. Procurando criar facilitadores de elaboração narrativa para os alunos neste momento, encontrei uma esperança nas atividades feitas e nas dúvidas apresentadas. Por que pensar na elaboração narrativa neste momento? Michèle Petit $(2009$, p. 42) nos diz que a arte da narrativa permite organizar a própria história e transformá-la, mas, para além de organizar a própria história, a arte da narrativa nos permite elaborá-la, e essa tem sido a minha principal preocupação neste momento com relação aos meus alunos.

\footnotetext{
${ }^{5}$ Disponível em: https://www.recantodasletras.com.br/poesiasdepaz/2216605. Acesso em: 20 jun. 2020.
} 
Realizar aquilo em que acreditamos é, contudo, tarefa complexa. Adaptar as atividades para as necessidades de nossos dias tem sido um desafio que demanda energia, por vezes esgotada. Porém, como professores e eternos pesquisadores que somos, não descansamos enquanto não julgamos encontrar a melhor maneira de agir. E, quando se faz possível propor uma atividade que seja o encontro entre o momento no qual estamos, as habilidades de aprendizagem e a criação de narrativas, cria-se um espaço potencial (WINNICOTT, 1975, p. 76) no qual há uma oportunidade para o nascimento da narrativa. Há, então, um espaço em que as atividades funcionam como objeto transicional, representando a presença do professor e da escola para o aluno. Por objeto transicional, transponho aqui um conceito psicanalítico elaborado por Donald Winnicott, em que ele descreve o ato de transferir a outros objetos os sentimentos a princípio desenvolvidos com os primeiros símbolos de afeto, como as mães. Os objetos transicionais fazem-se importantes para que as crianças consigam se manter em um estado psíquico de conforto e não decadência. Tomo, então a liberdade de dizer que nossas atividades podem ser esses objetos, pois são um dos únicos vínculos com os nossos alunos neste momento.

A experiência vivida com uma de minhas turmas de sexto ano pode ilustrar a importância da atividade para alunos e professores na atual circunstância. Pensando no que disse anteriormente, trabalhei relatos pessoais com os alunos e pedi que reportassem por escrito como tem sido esse momento para eles. Um aluno, ao escrever o seu, disse estar até gostando de ficar em casa, mas sentindo saudades dos amigos e da professora de LP (Língua Portuguesa). Ao ler seu relato, emocionei-me e senti o quanto eram importantes para mim as palavras dele. Para ele, o que tentei foi promover esse espaço para ele construir a narrativa, pensar e elaborar a escrita do que tem sido isso tudo. Para mim, representou um sinal de sobrevivência como professora.

Como disse anteriormente, nem sempre essas atividades são possíveis, e nós ficamos com o que é possível. Sem saber que em 2020 esse seria um tema tão recorrente, o primeiro texto que trabalhei com meus alunos dos oitavos anos foi "O possível"", de Marina Colasanti (2016). E como no texto - em que a personagem fica observando pássaros voarem e desejando voar, mas seu desejo não se torna real, vindo ela a galgar uma estátua equestre e defecar ali, sendo o possível para o seu sonho -, nós estamos sonhando e fazendo aquilo que conseguimos.

E o possível, para nós, tem sido comemorado a cada dia, pois, no meio de um cenário tão difícil pelo qual passamos, ainda precisamos de um grande esforço para que as ferramentas funcionem e as atividades sejam elaboradas da melhor maneira. Portanto, acredito que seja bom para o aluno que o professor se coloque também disponível para aprender e, sobretudo, para sentir-se como seus alunos se sentem diante do desconhecido. Assim, comemoramos todos os dias, ao conseguir aprender uma habilidade nova.

Há um efeito muito bonito de tudo isso que precisa ser compartilhado, um efeito revigorante e, mesmo, de muita esperança: os professores estão unidos. Nós estamos procurando apoio uns nos outros e temos encontrado aquilo que procuramos. Estamos inclusive conseguindo falar mais abertamente de sentimentos que sempre existiram na docência, mas eram símbolos de fraqueza, medo, insegurança. Agora falamos sobre eles e pedimos ajuda, rimos juntos, reclamamos juntos, pensamos juntos.

Com a paralisação das atividades rotineiras, inclusive na maneira de ensinar/aprender, nós paramos e estamos aprendendo, como sociedade, a importância das escolas; estamos aprendendo como professores o quanto abrir-se para o novo é bom, o quanto estarmos unidos faz com que sejamos melhores e o quanto precisamos lutar por espaços que nos ouçam.

6 Disponível em: https://www.marinacolasanti.com/2016/07/cronica-de-quinta-6-contos.html\#post-page-number-5. Acesso em: 01 de jun de 2020. 


\section{Pandemia, Isolamento Social e uma reflexão sobre o para quê e o para quem dos caminhos pedagógicos virtuais}

Quando anunciada a pandemia em razão do vírus COVID 19, iniciou-se na Secretaria de Educação do Estado de São Paulo a verificação de meios para que se mantivessem as aulas sem prejuízo do ano letivo. Desde então, nós, professores, temos enfrentado diversos problemas para adequar o uso da plataforma Centro de Mídias de São Paulo (CMSP) e de outros dispositivos.

Se, para os professores, as adaptações não foram fáceis, sem dúvida alguma, para pais e alunos a experiência tem sido ainda mais difícil. Lidar com o acompanhamento das aulas, dar suporte aos filhos no uso da internet e de plataformas são funções que claramente extrapolam as condições usuais da maioria deles. As propostas apresentadas não são acessíveis à realidade social de muitas das crianças da escola pública. Há orientação recorrente para que sejam utilizados aplicativos virtuais de encontros: Meet, Teams, Classroom. Enquanto tento contato com meus alunos pelo Whatsapp, contudo, questiono-me, em crise, para quê, para quem?

É fato que a plataforma CMSP é de grande ajuda para professores e alunos nesse momento de isolamento social. Apesar disso, fica claro que nenhuma plataforma substitui o professor e sua competência no exercício de alcançar e ensinar aos alunos. As atividades disponíveis nas plataformas são dirigidas a um aluno abstrato, genérico, e não têm como se atentar para as peculiaridades de aprendizagem de cada um. Especialmente entre alunos em situação de vulnerabilidade social, de zonas periféricas, reiteradamente desprivilegiados e estigmatizados, ignorar a dificuldade de acesso e a necessidade de encontro é desconsiderar por completo a pergunta sobre para quê, para quem? estamos fazendo tudo isso.

Possuo 8 turmas, sendo que cada uma tem uma média de 30 a 35 alunos. Para cada uma delas criei um grupo no Whatsapp, que se tornou o meio em que procuro garantir uma rotina de apoio, de estudos e de envio de atividades. Através desses grupos é possível também verificar quem está acompanhando as aulas no CMSP. A sala em que mais tenho alunos participando é a do $9^{\circ}$ ano de Língua Portuguesa. Nela, em média, 8 alunos têm acompanhado as aulas. Como, então, considerar que o trabalho tem chegado aos alunos e tem sido desenvolvido, senão por critérios meramente formais e burocráticos? Não por acaso, plataformas e dispositivos para aulas remotas reacendem a pergunta sobre para quê, para quem?.

Archangelo e Villela (2014, p. 51), no artigo "Crianças com problema de aprendizagem", afirmam que "[...] a escola pública atual marcada pelo discurso oficial da inclusão, da progressão continuada e do acompanhamento individualizado em sala de aula, paradoxalmente muitas vezes tende a impor, a alguns desses alunos, experiências de desamparo". Obviamente, não há caminhos e respostas simples para situação tão inusitada como a da pandemia, mas parece haver uma indisponibilidade para pensar o aluno a partir do aluno, a partir de uma posição empática em relação a ele e a suas peculiaridades.

A concepção da instituição escolar como um "estabelecimento formal destinado ao ensino coletivo" (FERREIRA, 2004, p. 285) já deveria ter sido superada. Para além dessa concepção, como aponta Winnicott, há muitas crianças e adolescentes "cujos lares, por alguma razão, são menos seguros, vêm à escola não tanto para aprender, mas para 'encontrar um lar fora do lar'", (DAVIS; WALLBRIDGE, 1982, p. 170). Silva (2019, p, 62), em uma analogia a esse apontamento de Winnicott, discorre "a respeito de uma instituição escolar que possa se apresentar como 'um lugar suficientemente bom' para abrigo, 'alojamento' de um público que busca nas relações da unidade escolar os parâmetros para a estabilidade emocional que não foi encontrada anteriormente, muitas vezes sequer no contexto familiar".

Por que, então, especialmente nesses tempos de pandemia, não pensar o acesso às atividades a partir das condições objetivas dos alunos, e de forma empática? Normalmente, eles moram na 
redondeza da escola; seria viável, portanto, tomando as precauções necessárias diante da necessidade de distanciamento, considerar a possibilidade de deixar roteiros e atividades semanais ou quinzenais em pastas que poderiam ser entregues e retiradas em suas casas. Pensar tais situações de acesso parece-me muito mais simples do que assimilar os casos diários de mães e pais que nos procuram, alegando, compreensivelmente, falta de condições para lidar com as inúmeras tarefas que chegam a seus celulares, da parte de diversos professores, de diferentes disciplinas, endereçadas a seus vários filhos, durante seu horário de trabalho. E é certamente mais lógico do que submeter os professores a uma rotina que não respeita seus horários de trabalho e mais adequado do que considerar vencidos os conteúdos que não têm sido alcançados pelos alunos. Novamente friso que toda uma logística precisaria ser elaborada, mas observo também que parte da dedicação aos dispositivos de ensino remoto poderia ser orientada para a preocupação em localizar os alunos que se perderam da escola nesse período e para reestabelecer o contato com eles.

Explica Silva (2019, p. 65) que "as necessidades individuais requerem das relações coletivas responsabilizações mútuas. A instabilidade ocasionada pela desarmonia social retira do sujeito sua capacidade de sentir-se parte, integrado, atado à vida de forma que se sinta significativo". Tal percepção corrobora a afirmação de Durkheim (2000) de que é nos laços solidários que o indivíduo percebe sua identificação social e, portanto, é nesses laços escolares que crianças e adolescentes deveriam encontrar disponibilidade para alojamento psíquico, em relações substitutivas que se oferecessem para alojamento, proteção, crescimento e aprendizagem (WINNICOTT, 1975).

O momento pandêmico deveria proporcionar a nós uma reflexão saudável sobre o motivo de ser de algumas coisas, porém parece-me que apenas agravou a falta de nexo perpetuada nos frios corredores relacionais que uma instituição como a escola deveria ter vencido. Faz-se necessário pensar nesse sujeito de forma que não seja mais um número a dar conta do ano letivo. Não obstante, persevera, ainda, em gestores do estado, das diretorias e até mesmo locais, uma indisponibilidade para pensar o ambiente escolar, virtual ou não, de forma a propor amplamente a inclusão de todos os alunos, sabendo que estão eles submetidos às mais diversas e adversas circunstâncias. $\mathrm{O}$ momento, por exemplo, seria ideal para saber, por meio das atividades deixadas em suas casas, onde e como moram nossos alunos. Isso permitiria ampliar o nosso olhar para muitas manifestações e comportamentos na escola, em relação aos quais muitas vezes nós, professores, somos intolerantes. Insisto nessa percepção, por acreditar que o viver em sociedade não nos oferece outra opção que não o pensar coletivamente, pois, como diz Silva (2019, p. 108):

Não é possível que o adoecimento individual não atinja os agrupamentos sociais - assim também, um mal social é transmitido às suas partes. A tristeza, a escassez, o sofrimento, a vulnerabilidade, a violência sofrida, a negligência vivida no âmbito individual atacam e avançam para a coletividade, para a vida social, robusta e vigorosamente.

Continuo, ainda, buscando pelos nexos do para quê e para quem, desejando muito que alcancemos a compreensão disso, a tempo de retornarmos ao desejado "volta às aulas presenciais".

\section{Conclusão}

As experiências narradas aqui vêm trazer um incômodo, mas também um convite sério, oportuno e urgente para refletir sobre o ambiente escolar com mais alma, numa perspectiva empática em relação a uma educação que seja pensada a partir do aluno e para o aluno. Apresentaram uma angústia comum, alimentada pelo desejo de contemplar todos os alunos e pelo questionamento a respeito das práticas pedagógicas vigentes, que muitas vezes ainda são 
pouco significativas e reprodutoras de atividades e de conteúdos descontextualizados. As provocações que os relatos enunciam carregam também um sonho que, mesmo em um tempo de tantas incertezas, permanece: um ambiente escolar que se ofereça como alojamento psíquico para crianças e adolescentes em situações de vulnerabilidade diversas. Esperamos que os educadores possam exercer com mais empatia, solidariedade e cuidado a prática pedagógica, e sejam menos pressionados pela burocracia. E que o maior comprometimento e preocupação com os mais vulneráveis pelo poder público não seja um sonho utópico.

\section{Referências}

ARCHANGELO, A.; VILLELA, F. Crianças com problema de aprendizagem. In: GALLO, Sílvio. As diferentes faces do racismo e suas implicações na escola. Campinas, SP: Leitura Crítica, 2014. p. 51-76.

BRASIL. Constituição da República Federativa do Brasil de 1988. Brasília, DF: Presidência da República Federativa do Brasil de 1988. Brasília, DF: Presidência da República, 2016.

BRASIL. Lei $n^{\circ}$ 8.069, de 13 de julho de 1990. Dispõe sobre o Estatuto da Criança e do Adolescente e dá outras providências. Brasília, 13 de julho de 1990.

DAVIS, M.; WALLBRIDGE, D. Limite e espaço: uma introdução à obra de D. W. Winnicott. Rio de Janeiro, RJ: Imago, 1982.

DURKHEIM, É. O suicídio. Tradução de Monica Stahel. São Paulo, SP: Martins Fontes, 2000.

FERREIRA, A. B. de H. Dicionário da Língua Portuguesa. Curitiba, PR: Posigraf, 2004.

PETIT, M. A arte de ler. Tradução de Arthur Bueno e Camila Boldrini. São Paulo, SP: Editora 34, 2009.

PIMENTA, S. G. et al. Saberes pedagógicos e atividade docente. 4. ed. São Paulo, SP: Cortez, 2005.

SILVA, R. C. dos S. S. Relações substitutivas no ambiente educacional socioeducativo (paradoxos entre limite e espaço). 2019. Dissertação (Mestrado em Educação) - Faculdade de Educação, Universidade Estadual de Campinas, Campinas, SP, 2019.

WINNICOTT, D. W. O brincar e a realidade. Tradução de José Octávio Aguiar de Abreu e Vanede Nobre. Rio de Janeiro, RJ: Imago, 1975.

WINNICOTT, D. W. O ambiente e os processos de maturação: estudos sobre a teoria do desenvolvimento emocional. Tradução de Irineo Constantino Schuch Ortiz. Porto Alegre, RS: Artmed, 1983.

\section{Sobre as autoras}

Lilian Cardoso de Mendonça é graduada em Letras e tem mestrado em Educação, todos pela Universidade Estadual de Campinas (UNICAMP). É professora contratada na rede Municipal 
de Ensino. Tem experiência na área de psicologia e educação, com pesquisa nos seguintes temas: psicanálise e educação, questões de gênero, literatura infantil.

E-mail: liliancardoso011@gmail.com.

Rosiane Cristina dos Santos Silva é graduada em Letras pela Faculdade de Americana (FAM) e Pedagogia pela Universidade Nove de Julho (UNINOVE), tem mestrado em Educação e Doutorado em curso em Educação, ambos pela Universidade Estadual de Campinas (UNICAMP). É professora da rede Estadual de Ensino, já atuou na coordenação pedagógica da Educação Básica e profissional pedagógico da Fundação CASA.

E-mail: rosianesantos0509@yahoo.com.

Sabrina Spanollo Rossetti é graduada em Fonoaudiologia pelo Instituto Metodista de Educação e Cultura (IMEC) e Pedagogia pela Universidade do Norte do Paraná (UNOPAR), tem especialização em psicomotricidade pela Faculdade Porto-Alegrense de Educação, Ciências e Letras (FAPA). É professora de educação fundamental da rede Municipal de Campinas, SP.

E-mail: sabrina.spagnollo@gmail.com.

Ana Archangelo é graduada em Psicologia pela PUC-SP (1988); Mestre (1995), Doutora (1999) e Livre-Docente (2019) pela UNICAMP. Professora na graduação e na pós-graduação da Faculdade de Educação da UNICAMP. Líder do grupo de pesquisa DiS (Diferenças e subjetividades em Educação) junto ao CNPq. Entre outros artigos e capítulos de livros, nacionais e internacionais, é autora do livro "O amor e o ódio na vida do professor", pela editora Cortez, e juntamente com Fabio Villela, dos 4 volumes da coleção "Escola significativa", publicada pela editora Loyola.

E-mail: ana.archangelo@gmail.com. 